\title{
Experimental investigations on core drilling by ultrasonic-vibration-assisted grinding for hard-to-machine materials - a review
}

\author{
Na Qin* \\ School of Mechanical Engineering, \\ Southwest Jiaotong University, \\ Chengdu, Sichuan 610031, China \\ Email: tinaspirit@home.swjtu.edu.cn \\ *Corresponding author

\section{Jingwen Lei} \\ Midea International, \\ B20 Midea HQ Building, No. 6 Midea Avenue, \\ Shunde, Guangdong 528000, China
}

\section{Z.J. Pei}

Department of Industrial and Manufacturing Systems Engineering, Kansas State University, Manhattan, KS 66506, USA

\begin{abstract}
Ultrasonic-vibration-assisted grinding (UVAG), a hybrid machining process combining material removal mechanisms of diamond grinding and ultrasonic machining, has been used to machine various hard-to-machine materials. Large amount of research work on UVAG has been carried out since it is invented. However there are few review papers to cover the current literature on UVAG. The emphasis of this literature review is the experimental investigations of the drilling process with ultrasonic vibration using a core drill with metal-bonded diamond abrasives. Experimental results are summarised and compared. The inconsistent results and their reasons are discussed. Furthermore, directions of future research on UVAG are also presented.
\end{abstract}

[Received 2 April 2015; Revised 30 November 2015; Accepted 2 December 2015]

Keywords: ultrasonic vibration assisted grinding; UVAG; hard-to-machine material; experimental investigation.

Reference to this paper should be made as follows: Qin, N., Lei, J. and Pei, Z.J. (2016) 'Experimental investigations on core drilling by ultrasonic-vibration-assisted grinding for hard-to-machine materials a review', Int. J. Manufacturing Research, Vol. 11, No. 1, pp.28-52. 
Biographical notes: $\mathrm{Na}$ Qin received her two $\mathrm{PhD}$ degrees from Kansas State University and Dalian University of Technology, Dalian, China, separately. She is currently working in Southwest Jiaotong University, Chengdu, China. Her research interest is ultrasonic-vibration-assisted grinding of hard-to-machining materials. She has been doing this research for about eight years.

Jingwen Lei received his Master's degree in Mechanical Engineering from Southwest Jiaotong University, Chengdu, China. He is currently a specialist in supply chain of Guangdong Midea, Guangdong, China. His research interest is ultrasonic-vibration-assisted grinding of titanium alloy.

Z.J. Pei received his $\mathrm{PhD}$ in Mechanical Engineering from University of Illinois at Urbana-Champaign. He is currently a Professor in Department of Industrial and Manufacturing Systems Engineering at Kansas State University. He holds three US patents and has published 100 journal papers and 120 conference papers. His current research activities include energy manufacturing as well as traditional and non-traditional machining processes.

\section{Introduction}

Ultrasonic-vibration-assisted grinding (UVAG), also known as rotary ultrasonic machining (RUM), is a hybrid process which combines material removal mechanisms of ultrasonic machining and diamond grinding. UVAG has the potential for high material removal rate (MRR) and clean cuts (Prabhakar, 1992). It is reported that UVAG has six to ten times higher MRR than traditional grinding (Prabhakar et al., 1992), and it is about ten times faster than ultrasonic machining (USM) (Cleave, 1976). Tool pressure and torque in UVAG are low (Cleave, 1976; Cusumano et al., 1974; Cong et al., 2011, 2013a, 2012c, 2012d): lower pressure is especially helpful when drilling small holes, deep holes, or adjacent holes with thin dividing walls (Cleave, 1976). UVAG also has reduced edge chipping, breakout and damage (Cleave, 1976). In addition, UVAG can easily fit in with traditional machines with some modifications (Prabhakar, 1992) and it can increase hole accuracy and reduce tool wear (Markov, 1977). Furthermore, Churi et al. (2005) demonstrated the feasibility of using UVAG to drill holes in ductile materials (titanium alloy). They presented that tool wear rate was about $85 \%$ lower, cutting force and surface roughness also reduced with ultrasonic-vibration-assisted machining.

Large amount of research work on UVAG has been carried out since it is invented in 1964. In 1995, Pei et al. summarised the literature on UVAG of structure ceramics. They reviewed the development history of UVAG process and equipment, experimental and theoretical studies. Zeng et al. (2004, 2006) reviewed the literature on UVAG of ceramics, including MRR modeling, effects of five input variables on MRR and tool wear. In 2007, Churi et al. (2007a) summarised the literature on UVAG of hard-to-machine materials, including alumina, silicon carbide, ceramic matrix composites $(\mathrm{CMC})$ and titanium alloys. They reviewed effects of three input variables (rotational speed, feedrate, and ultrasonic power) on UVAG performances (cutting force, surface roughness, and edge chipping). Kumar et al. (2013) made a comprehensive review for stationary USM and rotary mode USM as well as hybrid USM. Due to the advantage of UVAG, more UVAG research results have been reported after these review papers 
published, especially UVAG has been applied to new kinds of materials (like carbon fibre composites) and more input and output variables have been involved in experimental investigations. However, there are no systematical reviews to include the new results.

This paper reviews experimental investigations on UVAG (while theoretical investigations and modelling work as well as equipment designs will be reviewed in separate papers). It summarises what has been done and what has not yet, as well as some inconsistent results in the literature. Directions of future research on UVAG are also discussed.

This paper is organised into ten sections. Following this introduction section, Section 2 provides definitions and significance of UVAG input variables as well as typical values of these variables used in experiments. Sections 3 to 8 present experimental investigations on six UVAG output variables (MRR, surface roughness, cutting force and torque, tool wear, edge chipping, and surface and subsurface damage), respectively. Two new cutting methods, rotary ultrasonic elliptical machining (RUEM) and UVAG with variable feedrate, are also introduced in Section 9. Section 10 contains concluding remarks.

\section{Definitions and significance of UVAG input variables}

Figure1 is a schematic illustration of UVAG. A rotating core drill with metal-bonded diamond abrasive is ultrasonically vibrated while being fed into the workpiece at a constant pressure or a constant feed rate. Coolant pumped through the core of the drill washes away the swarf, prevents jamming of the drill and keeps it cool (Prabhakar, 1992).

Figure 1 Illustration of UVAG (see online version for colours)

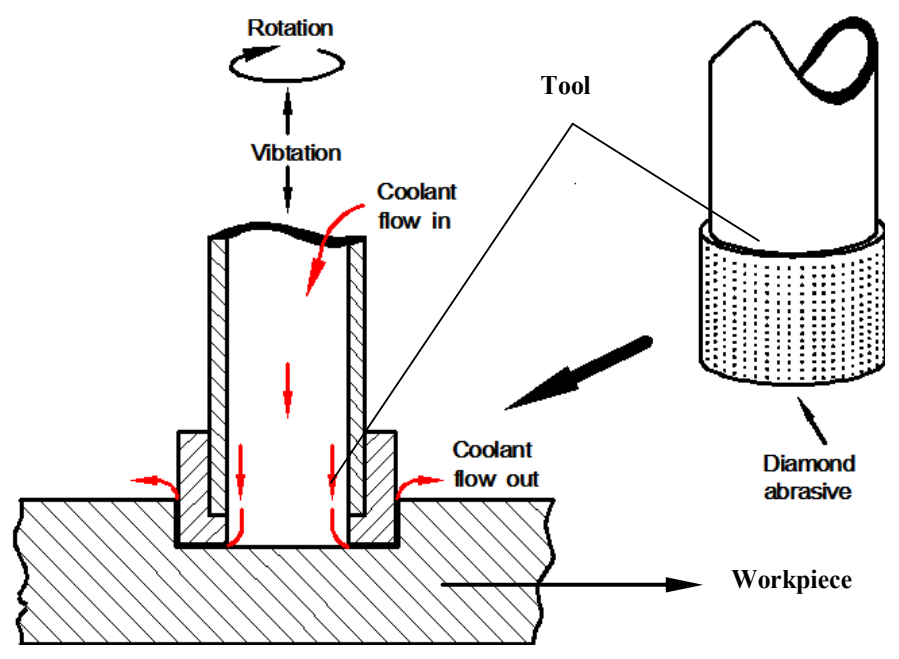

Source: Prabhakar (1992)

In this paper, experimental investigations using two types of machines (constant feedrate and constant pressure) are included. For the type of machines with constant feedrate, constant feedrate is applied on the tool (or workpiece) to feed the tool (or workpiece) 
towards the workpiece (or tool), and cutting force is an output variable. For the other type of machines, constant pressure is applied on the tool (or workpiece) to feed the tool (orworkpiece) towards the workpiece (or tool), and feedrate is an output variable. Important input variables in UVAG can be classified into three categories:

- $\quad$ variables related to cutting tool: diamond type, diamond grain size, diamond concentration, bond type, tool geometry (number of slots, outer diameter, chamfer direction and angle, and wall thickness)

- $\quad$ variables related to process: ultrasonic vibration amplitude, ultrasonic vibration frequency, tool rotational speed, and feedrateor pressure

- $\quad$ other variables: workpiece material type, coolant type and delivery mode, and support length of workpiece.

\subsection{Diamond type}

The cutting tool used in UVAG is a core drill. The end portion of the drill contains bonded abrasives, as shown in Figure 1. Diamond grains are commonlyused in UVAG (Salmon, 1992). Two types of diamond are reported for UVAG: natural and synthetic diamond (Prabhakar et al., 1993).

One grade of nature diamond (A16) and three grades of synthetic diamond (SAM, ASP 16, ASV16) were reported (Petrukha, 1970).

\subsection{Diamond grain size}

The grain size of diamond abrasive in UVAG is usually expressed as mesh size. It corresponds to the number of openings per linear inch in the wire gauze used to 'size' abrasive grains. But this wire gauze is employed primarily for sizes ranging from mesh \#4 to mesh \#240 (Salmon, 1992). For smaller grain sizes, the diameter of the abrasive grains is used to express the abrasive grain size.

Different diamond grain sizes are reported in UVAG. For example, mesh 60-800 (Kubota et al., 1977), mesh 100-240 (Hards, 1966), mesh 280 (Anantha Ramu et al., 1989), mesh 80 (Ya et al., 2001), mesh 325, mesh 500, mesh 600, mesh 800 (Wang and Lin, 1993), mesh 40/50, mesh 40/170, mesh 60/80, mesh 80/100 (Churi et al., 2007d), mesh 270/325 (Jiao et al., 2005b), mesh 315/400 (Markov, 1977), 50-220 $\mu \mathrm{m}$ (Prabhakar, 1992), 50-250 $\mu \mathrm{m}$ (Prtrukha, 1970), and $181 \mu \mathrm{m}$ (Dam et al., 1993).

\subsection{Diamond concentration}

Diamond concentration is defined as the weight of the diamond in each cubic inch of the bond material. 'When 72 carats of diamonds are added in 1 cubic inch of bond material, then the diamond concentration is called as 100 concentration' (Web, http1://www.diamondbladeselect.com); when 54 carats of diamond grains are added in 1 cubic inch of bond material, then the diamond concentration is called as 75 concentration. Each increase or decrease of 18 carats will cause the concentration to change by $25 \%$ (Web, http $1: / /$ www.diamondbladeselect.com).

Diamond concentration is one of the crucial characteristics of diamond tools (Prtrukha, 1970). It is related to the grinding or cutting efficiency and the machining 
costs. If the concentration is too high, many diamonds will fall off the tool prematurely, resulting in waste of the diamonds. If it is too low, the grinding efficiency will be reduced (Web, http1://www.diamondbladeselect.com). In reported investigations on UVAG of brittle materials, the concentration used ranged from 50 to 200 (Cusumano et al., 1974; Markov, 1977; Kubota et al.;1977; Prtrukha, 1970; Tyrrell, 1970).

\subsection{Bond type}

Bond material in the cutting tool holds diamond grains in place (Kim et al., 2001; Stoica et al., 2003). The physical and mechanical properties of the bond substantially influence the cutting properties of a diamond tool (Prtrukha, 1970). There are three common types of bond: resin, ceramic, and metal (Tyrrell, 1970). Brazed and electroplated are two methods for fabricating metal bonded diamond abrasive tools for UVAG. Electroplated tools offer a mechanical bond holding the diamond to the substrate while brazed tools offer a chemical bond holding the diamond to the substrate.

Bond-types affects workpiece/tool hardness ratio. This ratio is inversely proportional to penetration depth of an diamond into workpiece. Consequently, different bond-types result in different penetration depth of diamond into workpiece (Prabhakar, 1992).

Diamondtools with metal bonds are used in UVAG (Prabhakar, 1992; Markov, 1977; Kubota et al., 1977; Hards, 1966; Ya et al., 2001; Legge, 1964). Bronze-bonded, steel-bonded, brass-copper alloy and iron-nickel alloy were reported.

\subsection{Tool geometry}

Slots are designed on the end surface of cutting tool as shown in Figure 2. The number of slots is typically 0,2 , or 4 . It will influence the coolant flow rate and MRR, surface roughness of workpiece, cutting force, and tool wear (Churi et al., 2005; Zeng et al., 2008).

Figure 2 Illustration of UVAG cutting tool with slots

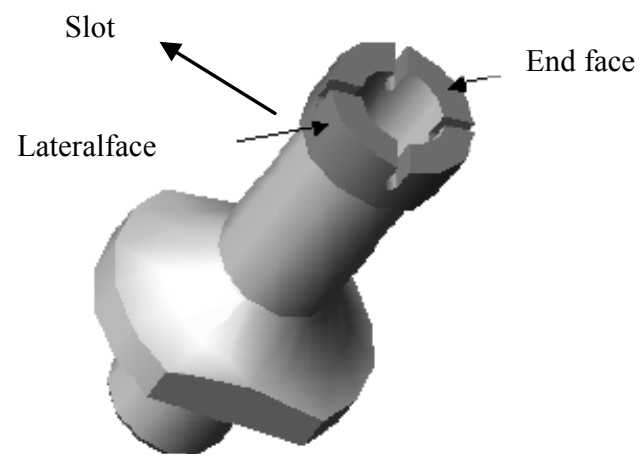

Source: Churi et al. (2005)

Since the cutting tool is hollow, it has outer and inner diameters. Wall thickness is $1 / 2$ of the difference between outer diameter and inner diameter. Wall thickness has a significant effect on MRR and cutting force (Komaraiah and Reddy, 1991; Li et al., $2005 \mathrm{c})$. In addition, according to the chamfer direction, three types of tool are defined: 
normal, inner and outer tools, as shown in Figure 3. Also, chamfer direction and angle, and wall thickness have significant effects on edge chipping (Qin et al., 2010).

Figure 3 Schematic illustrations of three cutting tools, (a) normal tool (b) inner tool (c) outer tool

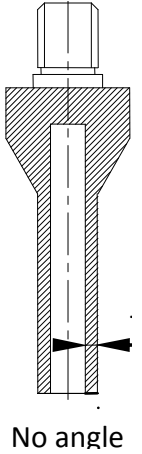

(a)

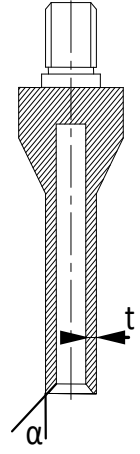

(b)

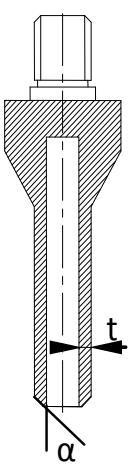

(c)

Source: Qin et al. (2010)

\subsection{Ultrasonic vibration amplitude}

Ultrasonic vibration amplitude of the diamond tool is an important input variable since it is a measure of the amount of energy input per cycle (Prabhakar et al., 1992; Markov, 1977). The vibration amplitude of tool for different power settings can be measured by an optical vibration sensing system. Power settings ranging from 0 to $100 \%$ are related to different vibration amplitudes (Prabhakar et al., 1992). Both power percentage and vibration amplitude are used to express the vibration amplitude of diamond tool. The vibration amplitude can be indicated directly on some new UVAG device.

In the literature, vibration amplitude is expressed by $\mu \mathrm{m}$ or power percentage.

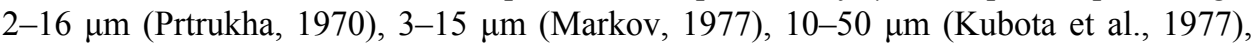

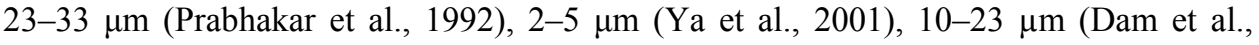
1993), and 20-50\% (Churi et al., 2005, 2009) were reported.

\subsection{Ultrasonic vibration frequency}

The following ultrasonic vibration frequency values were reported in the literature: 24.5-43.5 kHz (Prtrukha, 1970), 42.5 kHz (Markov, 1977), 17.4-40 kHz (Kubota et al., 1977), 20 kHz (Prabhakar et al., 1992; Ya et al., 2001), 16-24 kHz (Legge, 1964), 16, 20, 40 kHz (Cusumano et al., 1974), and 19.5-20.5 kHz (Dam et al., 1993).

\subsection{Rotational speed}

Rotational speed refers to the rotational speed (rpm, or revolution per minute) of workpiece or cutting tool. Either of them rotates around the axis of symmetry at a certain speed during UVAG.

The following rotational speeds have been reported in the literature: 2,420 rpm (Prtrukha, 1970), 2,000 rpm (Markov, 1977), 900 rpm (Kubota et al., 1977; Kremer et al., 1991), 1,000-3,000 rpm (Prabhakar et al., 1992), 450-540 rpm (Ya et al., 2001), 4,000- 
6,100 rpm (Cusumano et al., 1974), 0-5,000 rpm (Dam et al., 1993), 500-1,600 rpm (Hards, 1966), 2,000-5,000 (Churi et al., 2009), and 50-5,000 rpm (Graff, 1975).

\subsection{Feedrate}

Feedrate refers to the rate at which cutting tool (or workpiece) is fed towards workpiece (or tool). The feedrates are reported in the literature: $0.55-1.16 \mathrm{~mm} / \mathrm{s}$ (Prtrukha, 1970), $0.07-1.67 \mathrm{~mm} / \mathrm{s}$ (Ya et al., 2001), 0.06-0.25, 0.06, 0.25, 0.01, 0.09-0.15, 0.02-0.05, and 0.09-0.16 mm/s (Churi et al., 2007b, 2007d, 2009, 2006; Jiao et al., 2005a, 2005b; Li et al., 2004a, 2004b, 2005b, 2005c).

\subsection{Constant pressure}

Constant pressure is generated by the feed system (Prabhakar et al., 1993). Constant pressure has a great effect on an MRR for constant pressure machines (Pei et al., 1995). In the literature, the values of constant pressure were reported: 3-4 psi (Hards, 1966), 22-32 psi (Prabhakar et al., 1992), 427 psi (Prtrukha, 1970), 100-1,137 psi (Kubota et al., 1977), and 284-1,137 psi (Markov, 1977).

\subsection{Workpiece material type}

There are many workpiece material types reported in the literature, and they can be classified into three types: brittle materials, ductile materials and carbon fibre composites. Several brittle materials $\left(\mathrm{Al}_{2} \mathrm{O}_{3}\right.$, dental ceramics, $\mathrm{SiC}$, poly-crystalline, $\mathrm{Mg} / \mathrm{ZirO} \mathrm{O}_{2}$, kotassium dihydrogen phosphate (KDP) glass, silicon, $\mathrm{CMC}$, and two carbon fibre composites $[\mathrm{C} / \mathrm{C}$ composite, and carbon fibre-reinforced plastic (CFRP)] and two ductile materials (titanium and stainless steel)were reported.

\subsection{Coolant type and delivery mode}

Two coolant types were reported: fluid and cold air. Two coolant delivery modes have been investigated: continuous mode and intermittent mode. With continuous mode, coolant is delivered at a constant pressure, as shown in Figure 4(a). Currently, it is the dominant coolant delivery mode. Intermittent model delivers coolant at alternative pressures which alter between on and off states, as shown in Figure 4(b). It was found that intermittent mode has a positive effect on UVAG process compared with continuous mode (Li et al., 2005b).

Figure 4 Different coolant delivery modes in UVAG
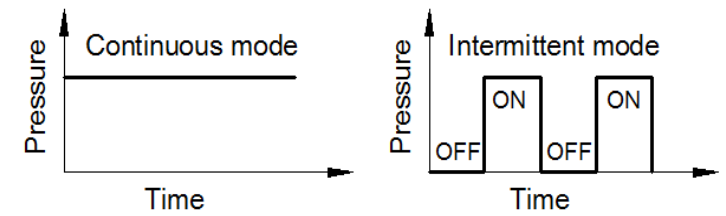

Source: Li et al. (2005b) 


\subsection{Support length of workpiece}

Support length of workpiece is the radial length of the contact area between workpiece bottom surface and fixture, as shown in Figure 5. It is determined by the diameter of the hole in the fixture. This hole is used to receive the rod drilled from workpiece (Li et al., 2006).

Figure 5 Schematic illustration of support length of workpiece in UVAG (see online version for colours)

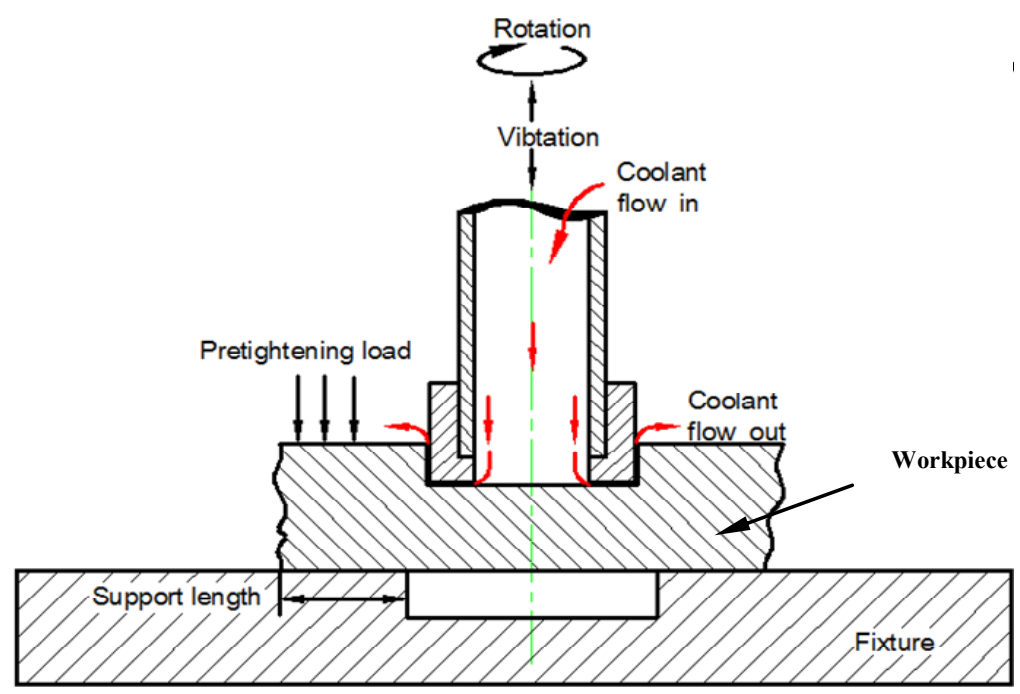

Source: Li et al. (2006)

\section{Experimental investigations on MRR}

MRR in UVAG was calculated by the following equation (Prabhakar, 1992; Churi et al., 2005, 2006; Li et al. 2005a, 2005b; Jiao et al., 2005a):

$$
\mathrm{MRR}=\frac{\text { Volume of material removed }}{\text { Time }}=\frac{\frac{\pi L\left(D_{o}^{2}\right)}{4}-\left(\frac{D_{i}^{2}}{4}\right)}{R}
$$

where $D_{o}$ is outer diameter of cutting tool, $D_{i}$ inner diameter of cutting tool, $L$ length of drilled hole, and $T$ the time it takes to drill the hole. 
Table 1 Experimental investigations on MRR in UVAG

\begin{tabular}{|c|c|c|}
\hline \multirow{2}{*}{ Input variable } & \multicolumn{2}{|c|}{ Workpiece material } \\
\hline & Ductile material & Brittle material \\
\hline Diamond grain size & $*$ & $\mathrm{Al}_{2} \mathrm{O}_{3}, \mathrm{Mg} / \mathrm{ZrO}_{2}$, glass \\
\hline Diamond concentration & $*$ & Glass \\
\hline Diamond type & $*$ & Glass \\
\hline Bond type & $*$ & $\mathrm{Mg} / \mathrm{ZrO}_{2}$, glass \\
\hline Vibration amplitude & $\mathrm{Ti}$ & $\mathrm{Al}_{2} \mathrm{O}_{3}, \mathrm{CMC}, \mathrm{Mg} / \mathrm{ZrO}_{2}$, glass \\
\hline Vibration frequency & $*$ & Glass \\
\hline Rotational speed & $\mathrm{Ti}$ & $\mathrm{Al}_{2} \mathrm{O}_{3}, \mathrm{CMC}, \mathrm{Mg} / \mathrm{ZrO}_{2}$, glass \\
\hline Feedrate & $\mathrm{Ti}$ & $\mathrm{Al}_{2} \mathrm{O}_{3}, \mathrm{CMC}$ \\
\hline Workpiece material & $*$ & $*$ \\
\hline Support length & $*$ & $*$ \\
\hline Tool design & $\mathrm{Ti}$ & $\mathrm{Al}_{2} \mathrm{O}_{3}$ \\
\hline Static force & $*$ & $\mathrm{Mg} / \mathrm{ZrO}_{2}$, glass \\
\hline Coolant and delivery mode & $*$ & $*$ \\
\hline
\end{tabular}

Note: * Means that no reports are available

Table 1 summarises experimental investigations on MRR reported in the literature. Five workpiece materials ( $\mathrm{Ti}, \mathrm{Al}_{2} \mathrm{O}_{3}, \mathrm{CMC}, \mathrm{Mg} / \mathrm{ZrO}_{2}$, glass) were tested, and ten of the 13 variables described in Section 2 were studied for brittle materials and only four of them were studied for ductile materials. The materials are classified into three types: ductile, brittle materials and carbon fibre composite as shown in all the tables.

Using a constant federate machine, only feedrate has significant effect on MRR in UVAG of Ti and alumina, and MRR was proportional to federate (Churi et al., 2005, 2006). While in UVAG of CMC, MRR was not only affected by feedrate, but also by rotational speed and vibration amplitude. MRR increased with increase of all of the three input variables, but no interaction effects were found (Li et al., 2005a). However, in UVAG of alumina, feedrate, rotational speed and vibration amplitude have significant three-factor interaction effects on MRR (Jiao et al., 2005a).

For experimental investigations using a constant pressure machine, two types of workpiece materials $(\mathrm{Mg} / \mathrm{ZrO}$ and glass) were tested. In $\mathrm{UVAG}$ of $\mathrm{Mg} / \mathrm{ZrO}$, four inputs variables (constant pressure, vibration amplitude, rotational speed, and grain size) have significant effects on MRR and pressure has the most significant effects. MRR increased with increase of all the four input variables. There existed some two-factor interaction effects on MRR (Prabhakar et al., 1992). In UVAG of glass, with increase of vibration amplitude, pressure and diamond concentration, MRR increased first, and then decreased. In addition, high strength synthetic diamond (synthetic diamond single-crystals, SAM) gives higher MRR than natural diamond, but natural diamond has a lower wear rate and smaller surface roughness than synthetic diamond (Prtrukha, 1970). As rotational speed and feedrate increased, MRR increased (Markov, 1977; Kubota et al., 1977; Ya et al., 2001; Prtrukha, 1970). 
It can be seen that, when it comes to MRR, for constant pressure machines, reported results are consistent. Most of the input variables have significant effects on MRR, and there exist two interaction effects. While for constant federate machines, theoretically MRR can be expressed as:

$$
M R R=\pi V\left[\left(\frac{D_{o}^{2}}{4}\right)-\left(\frac{D_{i}^{2}}{4}\right)\right]
$$

So it should be that the feedrate have the most significant effect on MRR, but this is not the case with experimental results. In UVAG of Ti (titanium and its alloy) (ductile material) and alumina (brittle material), the feedrate is indeed the dominant factor, but for CMC (also brittle material), three variables (rotational speed, feedrate, and ultrasonic power) are important. The mechanical property of workpiece may act as an important factor in UVAG. But no effects of workpiece mechanical property on MRR have been reported. In addition, interaction effects were observed in UVAG of alumina, but not in Ti and CMC. In fact, it is not trivial to find all the interaction effects by experiment since there are so many factors in the machining process. Thus, the best way to examine the interaction effects of factors is to find the machining mechanism.

\section{Experimental investigations on surface roughness}

Surface roughness $(\mathrm{Ra})$ of both machined rod surface and hole surface is measured along the feed direction by a surface profilometer (contact mode) (Zeng et al., 2004; Churi et al., 2005, 2009, 2006, 2007a, 2007b; Cong et al., 2009a, 200b, 2010; Feng et al., 2012). It is also measured by microscope ZKM01-250C (non-contact mode) (Wang and Lin, 1993). Although the stylus method more accurately records the axial cross-section profile of the drilled hole, the travelling length is limited, and it is not easy to adjust the instrument vs. specimen. $R_{a}, P_{t}$ and $R_{q}$ were used to measure the surface roughness of the hole (Wang and Lin, 1993), where $P_{t}$ was the vertical distance between the highest peak and the lowest valley of the unfiltered profile (Thomas, 1999).

Experimental investigations on surface roughness reported in the literature are summarised in Table 2. Six brittle materials $\left(\mathrm{Al}_{2} \mathrm{O}_{3}\right.$, dental ceramics, $\mathrm{SiC}$, poly-crystalline, glass, KDP), two ductile materials ( $\mathrm{Ti}$ and stainless steel) and two composite material (C/C, CFRP) were studied. Ten of the 13 parameters as described in Section 2 were studied for brittle materials and seven of them were studied for ductile materials.

Compared with traditional diamond grinding, UVAG produces lower Ra. Ra also can be improved by applying different coolant delivery modes (continuous mode and intermittent mode) and different coolant type (cold air or cutting fluid) (Cong et al., 2011; $\mathrm{Li}$ et al., 2005b). Tool slots have different influences on surface roughness for different workpiece material. In UVAG of Ti, higher Ra was observed with slots than without slots. But in UVAG of hot-press alumina, better Ra was obtained with slots (Churi et al., 2005; Zeng et al., 2008). The reason has not been understood yet. For coolant type, Ra was lower using cutting fluid than using cold air (Cong et al., 2011). 
Table 2 Experimental investigations on surface roughness in UVAG

\begin{tabular}{|c|c|c|c|}
\hline \multirow[b]{2}{*}{ Input variable } & \multicolumn{3}{|c|}{ Workpiece material } \\
\hline & Ductile material & Brittle material & $\begin{array}{l}\text { Carbon fibre } \\
\text { composite }\end{array}$ \\
\hline Diamond grain size & $\mathrm{Ti}$ & $\begin{array}{c}\mathrm{Al}_{2} \mathrm{O}_{3}, \mathrm{SiC}, \text { glass, } \\
\text { Zerodur }\end{array}$ & $*$ \\
\hline Diamond concentration & $\mathrm{Ti}$ & Glass & $*$ \\
\hline Bond type & $\mathrm{Ti}$ & Glass & $*$ \\
\hline Diamond type & $*$ & Glass & $*$ \\
\hline Ultrasonic vibration amplitude & $\begin{array}{c}\text { Ti and stainless } \\
\text { steel }\end{array}$ & $\begin{array}{c}\mathrm{Al}_{2} \mathrm{O}_{3} \text {, dental ceramics, } \\
\text { SiC, glass }\end{array}$ & CFRP, CFRP/Ti \\
\hline Ultrasonic vibration frequency & $*$ & Glass & $*$ \\
\hline Rotational speed & $\begin{array}{c}\text { Ti and stainless } \\
\text { steel }\end{array}$ & $\begin{array}{c}\mathrm{Al}_{2} \mathrm{O}_{3} \text {, dental ceramics, } \\
\mathrm{SiC}, \mathrm{KDP}\end{array}$ & CFRP, CFRP/Ti \\
\hline Feedrate & $\begin{array}{c}\text { Ti and stainless } \\
\text { steel }\end{array}$ & $\begin{array}{c}\mathrm{Al}_{2} \mathrm{O}_{3} \text {, dental, ceramics, } \\
\mathrm{SiC}\end{array}$ & $\mathrm{C} / \mathrm{C}, \mathrm{CFRP}$ \\
\hline Coolant type and delivery mode & $*$ & $*$ & CFRP \\
\hline Workpiece material & $*$ & Poly-crystalline & $*$ \\
\hline Support length & * & $*$ & * \\
\hline Tool design & $\mathrm{Ti}$ & * & $*$ \\
\hline Static force & $*$ & Glass & $*$ \\
\hline
\end{tabular}

Ra was always proportional to diamond grain diameter and inversely proportional to rotational speed except for UVAG of dental ceramics and KDP (Wang et al., 2009). In UVAG of dental ceramics, Ra decreased first and then increased as rotational speed increased, while in UVAG of KDP, a reverse trend was obtained. Note that, the rotational speed ranged from $1,000 \mathrm{rpm}$ to $4,000 \mathrm{rpm}$ in UVAG of $\mathrm{Al}_{2} \mathrm{O}_{3}$ (Zeng et al., 2008), from 2,000 rpm to 5,000 rpm in UVAG of dental ceramics (Churi et al., 2009) and from 2,000 to 6,000 rpm in UVAG of KDP (Wang et al., 2009). The inconsistent results might be due to different materials and different choices of variable range, but no explanations have been provided in the literature.

When it comes to the effect of feedrate and vibration amplitude, inconsistent results were also reported. In UVAG of $\mathrm{SiC}, \mathrm{Ra}$ is proportional to federate (Churi et al., 2007d), in UVAG of $\mathrm{Al}_{2} \mathrm{O}_{3}$, feedrate had no obvious effects on Ra (Zeng et al., 2008) or Ra was proportional to federate (Jiao et al., 2005a), and in UVAG of dental ceramics, there existed an optimum feedrate that produced the lowest Ra (Churi et al., 2009). In addition, there were no interaction effects on Ra in UVAG of SiC (Churi et al., 2007d), while significant interaction effects existed in UVAG of $\mathrm{Al}_{2} \mathrm{O}_{3}$ and stainless steel (Jiao et al., 2005a; Cong et al., 2009a).

The most obvious inconsistence has been observed when it comes to the effect of vibration amplitude. In UVAG of dental ceramics, Ra increased first and then decreased as vibration amplitude increased (Prtrukha, 1970; Churi et al., 2009). In contrast, in UVAG of $\mathrm{Al}_{2} \mathrm{O}_{3}, \mathrm{Ra}$ decreased first and then increased (Zeng et al., 2008) or did not change much as vibration amplitude changed (Jiao et al., 2005a). In UVAG of SiC, Ra was inversely proportional to vibration amplitude (Churi et al., 2007d). Again, the 
inconsistent results might be due to different materials and different choices of variable range, but no explanations have been provided for the inconsistencies in the literature.

In order to explain why the surface roughness of the drilled hole entrance side is better than that of hole exit side, Cong et al. presented and tested three hypotheses. One of them was not rejected and the reason for prior mentioned phenomenon was that the location near the entrance side was ground longer than the location near the exit side (Cong et al. 2013b).

\section{Experimental investigations on cutting force and torque}

Cutting force can affect mechanical properties (fracture toughness and hardness) and microstructure of workpiece materials ( $\mathrm{Li}$ et al., 2005c). It is directly related to cutting temperature, surface roughness and accuracy of workpiece, and surface residual stress, etc. Cutting force was investigated in constant feedrate machines. The average or maximum cutting force along the feedrate direction was measured by a KISTLER 9257 dynamometer (Churi et al., 2007b, 2007d, 2005, 2009, 2006; Jiao et al., 2005a, 2005b; Li et al., 2005a, 2006; Cong et al., 2009a, 2009b, 2012a).

Tables 3 and 4 summarise experimental investigations on cutting force and torque reported in the literature. Seven brittle materials $\left(\mathrm{Al}_{2} \mathrm{O}_{3}, \mathrm{ZrO}_{2} / \mathrm{Al}_{2} \mathrm{O}_{3}\right.$, dental ceramics, $\mathrm{SiC}$, poly-crystalline, $\mathrm{CMC}$, and silicon), two ductile materials (Ti and stainless steel) and two carbon fibre composites (C/C, CFRP) were studied. Seven of the 13 input variables were studied for ductile materials, six of them for brittle materials and only two of them for carbon fibre composites (Cong et al., 2011, 2013a, 2012a, 2012b, 2012c; 2012d; Ma, 2013).

Table 3 Experimental investigations on cutting force in UVAG

\begin{tabular}{|c|c|c|c|}
\hline \multirow[b]{2}{*}{ Input variable } & \multicolumn{3}{|c|}{ Workpiece material } \\
\hline & Ductile material & Brittle material & $\begin{array}{l}\text { Carbon fibre } \\
\text { composite }\end{array}$ \\
\hline Diamond grain size & $\mathrm{Ti}$ & $\mathrm{Al}_{2} \mathrm{O}_{3}, \mathrm{SiC}$ & $*$ \\
\hline Diamond concentration & $\mathrm{Ti}$ & $*$ & $*$ \\
\hline Bond type & $\mathrm{Ti}$ & $*$ & * \\
\hline Diamond type & $*$ & $*$ & $*$ \\
\hline $\begin{array}{l}\text { Ultrasonic vibration } \\
\text { amplitude }\end{array}$ & $\begin{array}{l}\text { Ti and stainless } \\
\text { steel }\end{array}$ & $\begin{array}{c}\mathrm{Al}_{2} \mathrm{O}_{3}, \text { dental ceramics, } \mathrm{SiC}, \\
\mathrm{CMC}, \text { silicon }\end{array}$ & $*$ \\
\hline $\begin{array}{l}\text { Ultrasonic vibration } \\
\text { frequency }\end{array}$ & $*$ & $*$ & $*$ \\
\hline Rotational speed & $\begin{array}{l}\text { Ti and stainless } \\
\text { steel }\end{array}$ & $\begin{array}{c}\mathrm{Al}_{2} \mathrm{O}_{3}, \text { dental ceramics, } \mathrm{SiC}, \\
\text { CMC, silicon }\end{array}$ & $\begin{array}{l}\text { CFRP/Ti, } \\
\text { CFRP }, \mathrm{C} / \mathrm{C}\end{array}$ \\
\hline Coolant type & * & * & CFRP \\
\hline Feedrate & $\begin{array}{l}\text { Ti and stainless } \\
\text { steel }\end{array}$ & $\begin{array}{c}\mathrm{Al}_{2} \mathrm{O}_{3}, \text { dental ceramics, } \mathrm{SiC}, \\
\text { CMC, silicon }\end{array}$ & $*$ \\
\hline Workpiece material & $*$ & Poly-crystalline, $\mathrm{ZrO}_{2} / \mathrm{Al}_{2} \mathrm{O}_{3}$ & $*$ \\
\hline Support length & $*$ & $\mathrm{Al}_{2} \mathrm{O}_{3}$ & $*$ \\
\hline Tool design & $\mathrm{Ti}$ & $*$ & $*$ \\
\hline
\end{tabular}


Table 4 Experimental investigations on torque in UVAG

\begin{tabular}{lccc}
\hline & & Workpiece material & \\
\cline { 2 - 3 } Input variable & Ductile material & Brittle material & $\begin{array}{c}\text { Carbon fibre } \\
\text { composite }\end{array}$ \\
\hline Diamond grain size & $*$ & $*$ & $*$ \\
Diamond concentration & $*$ & $*$ & $*$ \\
Bond type & $*$ & $*$ & $*$ \\
Diamond type & $*$ & $*$ & $*$ \\
Ultrasonic vibration amplitude & Steel & $*$ & CFRP/Ti, CFRP \\
Ultrasonic vibration frequency & $*$ & $*$ & $*$ \\
Rotational speed & Steel & $*$ & CFRP/Ti, CFRP \\
Feedrate & Steel & $*$ & CFRP \\
Coolant type & $*$ & $*$ & CFRP \\
Workpiece Material & $*$ & $*$ & $*$ \\
Support length & $*$ & $*$ & $*$ \\
Tool design & Ti & $*$ & $*$ \\
Static force & $*$ & $*$ \\
\hline
\end{tabular}

There is a phenomena that cutting force in UVAG was lower than that in traditional diamond grinding. Zhao explained this phenomenon by the trajectory of diamond grits and the difficulty level of removing chips using experimental results and kinematic of diamond grits (Zhao et al., 2013). For drilling as shown in Figure 6, the difficulty level of removing chip was the main reason for cutting force difference. Since the end face was the main working area of the tool, with the help of ultrasonic vibration and effect of cavitations, it would be easier for chips to be washed away and for coolant to be going into the working area, resulting in low difficulty level of removing chip.

Figure 6 Schematic illustrations of the drilling processes

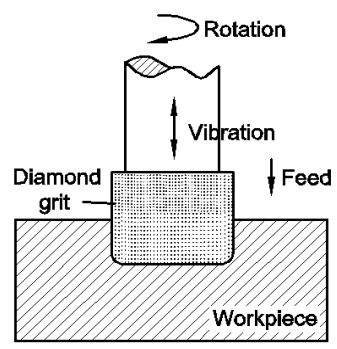

Source: Zhao et al. (2013)

Cutting force was also lower using tools with slots than without slots in UVAG of Ti (Churi et al., 2005; Zeng et al., 2008), but there was no obvious difference when drilling alumina (Zeng et al., 2008). Also, cutting force could be lower when using cutting fluid as coolant compared to using cold air (Cong et al., 2011). For all the experimental results given in the literature, cutting force increased with increase of feedrate and diamond size. But it decreased as rotational speed increased except for CMC. In UVAG of CMC, no obvious effects of rotational speed on cutting force were observed. 
Inconsistence also existed regarding vibration amplitude. Seven experiments have been conducted for UVAG, and six of them were for brittle materials and one for ductile material. Four of the seven were DOE experiments (design of experiment) for four workpiece materials ( $\mathrm{SiC}, \mathrm{CMC}, \mathrm{Al}_{2} \mathrm{O}_{3}$, stainless steel, and silicon). No obvious effects of vibration amplitude have shown in the DOE experiments of brittle materials except for silicon but obvious effects of vibration amplitude existed in UVAG of stainless steel. In the other two experiments, cutting force decreased first and then increased in one experiment, while decreased all the time in the other one as vibration amplitude increased. In addition, interaction effects existed in UVAG of $\mathrm{SiC}$, alumina, silicon and stainless steel, but not in UVAG of CMC.

Torque is one of the factors that determine the machining power in hole drilling. In UVAG, torque was measured by a KISTLER 9257 dynamometer. According to the literature, compared with twist drilling, torque was lower in UVAG of CFRP. In addition, torque decreased with the increase of ultrasonic vibration amplitude and tool rotational speed and the decrease of feedrate in UVAG of carbon fibre composites. Also, using variable feedrate method (explained in Section 9) or cutting fluid, torque could be lower than using a fixed feedrate method or cold air (Cong et al., 2011, 2013a, 2012c, 2012d).

\section{Experimental investigations on tool wear}

Tool wear is a significant index of the machinability for the machined material (Hocheng et al., 2000). Diamond grains on the tool may have attritious wear, grain fracture, grain pullout and catastrophic failure during machining process (Cho et al., 1994; Churi et al., 2007c; Hagiwara et al., 1994; Malkin, 1989; Sathyanarayanan and Pandit, 1985; Shi and Malkin, 2003; Xie et al., 2003). "Attritious wear refers to a type of wear where sharp edges of an abrasive grain becomedull due to attrition by workpiece material, developing flat areas" (Churi et al., 2007c; Malkin, 1989) as shown in Figure 7. "Attritious wear increases the area of wear flats and determines the magnitude of the grinding force and quality of the ground surface" (Churi et al., 2007c). Grain fracture causes the abrasive fragment to be removed within the grain and the fractured area exposes new cutting edges (Churi et al., 2007c). Grain pullout refers to a type of wear where the "diamond grains on the wheels were dislodged prematurely, before completing their effective working lives", as shown in Figure 8. Catastrophic failure refers to "cracking of metal bond and diamond grains occurring at macroscopic scale". This type of failure is undesirable since once it happens, the tool will fail (or break).

Figure 7 Attritious wear

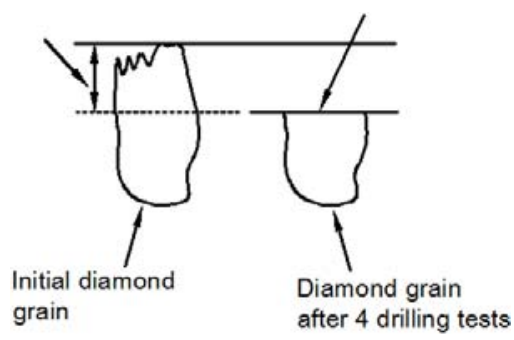

Source: Churi et al.(2007c) 
Figure 8 Diamond pull out

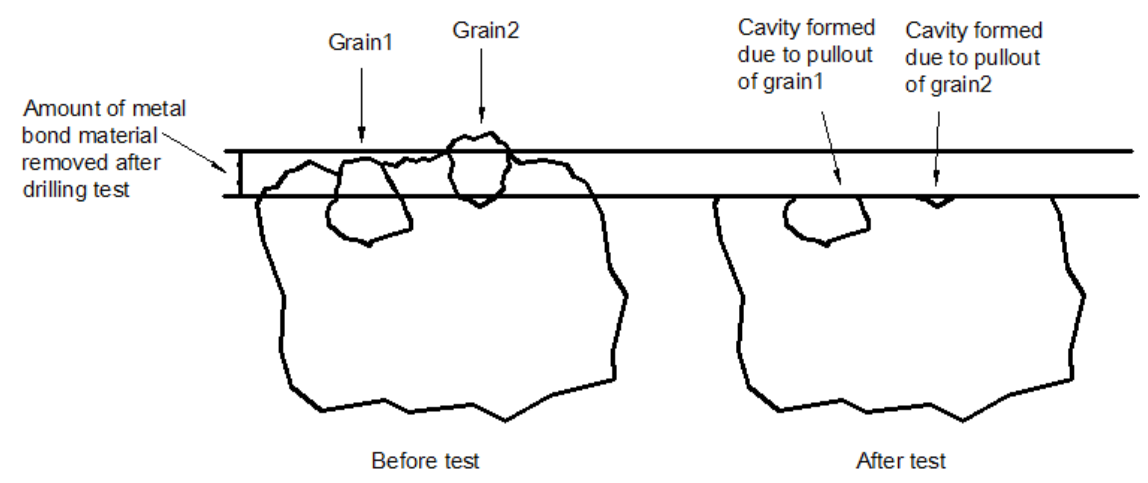

Source: Churi et al. (2007c)

Bond fracture may happen during diamond grinding (Churi et al., 2007c; Malkin, 1989; Shi and Malkin, 2003). It refers to a type of wear where the bond material is eroded. The bond strength is reduced and diamond grain dislodgement is promoted due to bond fracture. Sometimes, a certain amount of metal bond material was removed leading to the grain to be completely pulled leaving a cavity in the metal bond (Churi et al., 2007c).

In UVAG, tool wear was measured by the difference between two length measurements along the axial direction before and after each test. The tool length of the core drill was measured by a Vernier calliper (Churi et al., 2005, 2007c) or observed by digital microscope (Zeng et al., 2004). Tool wear was also defined as the weight loss of the cutting tool during each test (Cong et al., 2011, 2013a). Tool wear was also estimated by wear ratio which is the ratio of the volume of material removed by tool to the volume of tool wear (Prtrukha, 1970).

Table 5 Experimental investigations on tool wear in UVAG

\begin{tabular}{lccc}
\hline & & Workpiece material & \\
\cline { 2 - 4 } Input variable & Ductile material & Brittle material & $\begin{array}{c}\text { Carbon fibre } \\
\text { composite }\end{array}$ \\
\hline Diamond grain size & $\mathrm{Ti}$ & Glass & $*$ \\
Diamond concentration & $\mathrm{Ti}$ & Glass & $*$ \\
Bond type & $\mathrm{Ti}$ & Glass & $*$ \\
Diamond type & $*$ & Glass & $*$ \\
Ultrasonic vibration amplitude & $*$ & Glass & CFRP/Ti \\
Ultrasonic vibration frequency & $*$ & Glass & $*$ \\
Rotational speed & $*$ & $*$ & $\mathrm{CFRP} / \mathrm{Ti}$ \\
Feedrate & $*$ & $*$ & $*$ \\
Coolant type & $*$ & $*$ & $\mathrm{CFRP}$ \\
Workpiece material & $*$ & $*$ & $*$ \\
Support length & $*$ & $*$ & $*$ \\
Tool design & Ti & $*$ & $*$ \\
Static force & $*$ & & $*$ \\
\hline
\end{tabular}


Table 5 summarises experimental investigations on tool wear reported in the literature. One brittle material (glass), one ductile material (Ti) and one composite materials (CFRP) were tested by three researchers, respectively. Six of the 13 input variables were studied for glass, four for Ti, and three for CFRP.

Little research has been done for tool wear in UVAG. Some of these investigations were conducted to study influences of input variables on tool wear (Prtrukha, 1970; Churi et al., 2007b). Others were done to find the phenomena related to tool wear (Li et al., 2004b; Churi et al., 2007c; Zeng et al., 2005, 2009). Due to poor machinability of ductile material $\mathrm{Ti}$, more tool wear was observed in UVAG of Ti than in UVAG of brittle materials. In UVAG, tool wear is lower than that in diamond grinding. Moreover, tools with slots has higher wear rate than those without slots (Churi et al., 2005). Compared to using cold air as coolant, less tool wear was observed by using cutting fluid as coolant (Cong et al., 2011).

\section{Experimental investigations on edge chipping}

During UVAG of brittle materials, "there is a tendency for machined rod to break-off before the tool has cut through the workpiece. This phenomenon gives rise to edge chipping at the exit of hole" (Churi et al., 2009). It includes two parameters: chipping thickness and size, as shown in Figure 9. They were measured on the rod as shown in Figure 8 and measured by a Vernier calliper (Churi et al., 2009; Li et al., 2006).

Figure 9 Illustration of edge chipping and its measurement (see online version for colours)
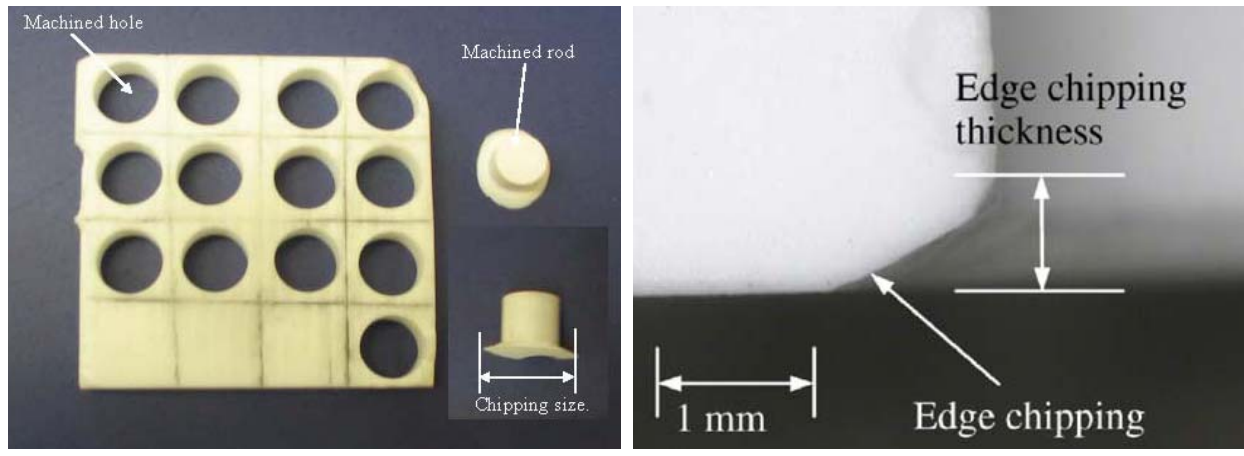

Source: Li et al. (2006)

Edge chipping is not acceptable on finished workpieces, since it "not only compromises geometric accuracy, but also causes possible failure of the component during service" (Ng et al., 1996), so it has to be machined off by extra processes after UVAG. The larger the edge chipping thickness, the higher the total machining cost. Therefore, research efforts to reduce edge chipping thickness in UVAG are desirable. Furthermore, it was stated that $\mathrm{Ra}$ is not enough to estimate hole quality in CMC drilling, and "chippings are the key barrier of drilling high-quality holes on CMC panels", so chipping size and thickness were utilised to estimate the hole quality in UVAG of CMC (Li et al., 2005a). 
Table 6 Experimental investigations on edge chipping in UVAG

\begin{tabular}{lc}
\hline Input variable & Brittle workpiece material \\
\hline Diamond grain size & $\mathrm{Al}_{2} \mathrm{O}_{3}, \mathrm{SiC}$ \\
Diamond concentration & $*$ \\
Bond type & $*$ \\
Diamond type & $*$ \\
Ultrasonic vibration amplitude & $\mathrm{Al}_{2} \mathrm{O}_{3}$, dental ceramics, $\mathrm{SiC}, \mathrm{CMC}$, silicon \\
Ultrasonic vibration frequency & $*$ \\
Rotational speed & $\mathrm{Al}_{2} \mathrm{O}_{3}$, dental ceramics, $\mathrm{SiC}, \mathrm{CMC}$, silicon \\
Feedrate & $\mathrm{Al}_{2} \mathrm{O}_{3}$, dental ceramics, $\mathrm{SiC}, \mathrm{CMC}$, silicon \\
Material mechanical property & $*$ \\
Support length & $*$ \\
Tool design & $\mathrm{Al}_{2} \mathrm{O}_{3}$ \\
Static force & $*$ \\
\hline
\end{tabular}

Experimental investigations on edge chipping of brittle materials are summarised in Table 6. Six materials and four input variables were studied by three researchers. It was found that chipping size was inversely proportional to rotational speed and diamond grain size and proportional to feedrate and vibration amplitude (Churi et al., 2007d, 2009; Jiao et al., 2005b; Li et al., 2005a, 2006; Ng et al., 1996). By integrating designed experiments and FEA simulations, Cong et al. (2012a) presented that tool rotational speed, ultrasonic power and feedrate have significant effects on edge chipping thickness, and higher rotational speed and vibration amplitude and lower feedrate led to lower edge chipping. In UVAG of $\mathrm{SiC}$ and silicon, no significant interactions have been found (Churi et al., 2007d; Cong et al., 2012a), while in UVAG of CMC and alumina, there existed interaction effects among inputs variables (Jiao et al., 2005b; Li et al., 2005a). In addition, it was reported that edge-chipping thickness could be reduced by increasing the support length ( $\mathrm{Li}$ et al., 2006, 2004a). For effects of tool design, tool angle and wall thickness and type of cutting tool had influences on edge chipping thickness. The outer tool had the lowest edge chipping thickness and size, while the normal tool had the highest edge chipping thickness and size (Qin et al., 2010).

\section{Experimental investigations on surface and subsurface damage}

Since UVAG is an abrasive machining process, it will cause surface damage (such as chipping and scratch) and subsurface damage (such as residual stress and subsurface cracks) when the workpiece is brittle material. These damages serve as potential sites for crack initiations and propagation as well as fracture failure.

With respect to experimental investigations on surface and subsurface damage, two materials have been studied: dental ceramics and glass K9 (Ahmed et al., 2012; Lv et al., 2012), as shown in Table 7. In order to observe the subsurface of workpiece, a bonded interface sectioning technique was selected by researchers. The interface of two specimens were first bonded together with adhesive and after machining, the bonded specimens were separated and cleaned. The subsurface damage layer was observed on the 
boned interface. Also, etching with Yang solution was done to make the subsurface cracks discernable. Scanning electron microscope (SEM) and microscope were used to observe the surface and subsurface damage (Lv et al., 2012, 2014).

Table 7 Experimental investigations on surface and subsurface damage

\begin{tabular}{lc}
\hline Input variable & Brittle workpiece material \\
\hline Diamond grain size & $*$ \\
Diamond concentration & $*$ \\
Bond type & $*$ \\
Diamond type & $\mathrm{Al}_{2} \mathrm{O}_{3}$ \\
Ultrasonic vibration amplitude & $*$ \\
Ultrasonic vibration frequency & $\mathrm{Glass} \mathrm{BK} 7$ \\
Rotational speed & $*$ \\
Feedrate & $*$ \\
Material mechanical property & $*$ \\
Support length & $*$ \\
Tool design & $*$ \\
Static force & $*$ \\
\hline
\end{tabular}

For dental ceramics, it was presented that the surface quality is better with ultrasonic vibration than without, the subsurface cracks and the depth of crack ranges are much less with ultrasonic vibration than without. However, subsurface cracks generation and propagation mechanism have not been well explained (Ahmed et al., 2012).

Figure 10 SEM micrograph of the UVAG surface (see online version for colours)

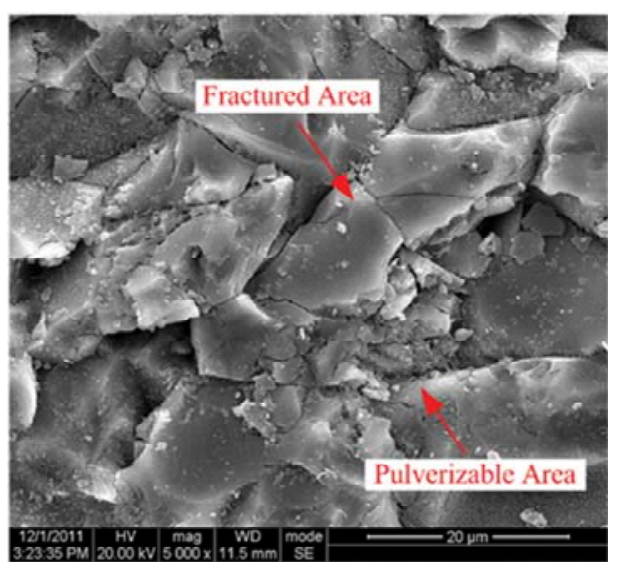

Source: Lv et al. (2014)

For UVAG of glass K9, three types of subsurface damage were identified as pulverisation, chipping, and cracking by Lv et al. The pulverisation layer was characterised by finer debris as shown in Figure 10; chippings were formed while lateral cracks extending to the workpiece surface. Cracking layer was beneath the chipping layer, the cracks obliquely extended further into the interior material, due to the 
complexity of the abrasive-material interactions. Lv et al concluded that pulverisation was formed due to the inertial effects of material aroused by the dynamic loading of the abrasive. They also presented that material pulverisation was the third material removal mechanism beside brittle fracture and plastic flow, and pulverisation areas gave prominence to the fracture areas (Lv et al., 2012). They found that unlike in traditional grinding, in UVAG the micro-cracks did not expand into the interior material and nucleated simultaneously, so it could be seen that plenty of micro-cracks, which pulverised the material, were populated near the top surface of the workpiece.

\section{Others}

Cong et al. proposed a variable feedrate method in UVAG of CFRP/Ti stack where low feedrate was used in UVAG of Ti while feedrate of 10 times higher was used in UVAG of CFRP. In other words, they changed the feedrate at the interface between CFRP and Ti for the CFRP/Ti stack. In their study, feedrates of $0.5 \mathrm{~mm} / \mathrm{s}$ and $0.05 \mathrm{~mm} / \mathrm{s}$ were chosen for CFRP and Ti respectively. Compared to the traditional constant feedrate, the cycle time for machining the stack was shorter, and the cutting force, torque and tool wear was lower under most machining conditions (Cong et al., 2013a).

Diamond tool life and quality of machined parts are strongly influenced by cutting temperature, and it is not easy to measure the real temperature when using cutting field. Zou et al. (2013) measured the point temperature by self-designed Fabry-Perot fibre optic sensor. They concluded that fibre optic sensor offers more accuracy point temperature and good durability against harsh environments than thermocouple measurement. The influence of input variables (ultrasonic power, spindle speed, and feedrate) on temperature were also studied. In the future, more inputs can be included to study the relationship between inputs and temperature by this temperature measuring method to have a comprehensive understanding of generation of temperature and temperature controlling techniques.

Figure 11 Illustration of UEVC process (see online version for colours)

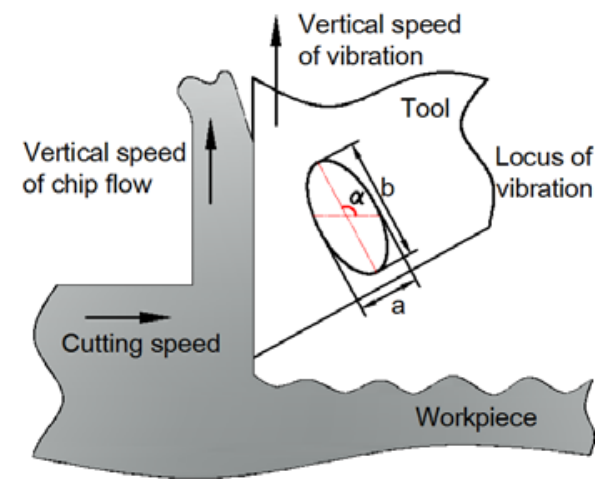

Source: Liu et al. (2012)

Recently, another new machining method, RUEM was proposed by Jing Liu et al. in for drilling holes on CFRP panels. RUEM is a hybrid of the UVAG and ultrasonic elliptical vibration cutting (UEVC). Figure 11 illustrates the UEVC process. In RUEM, a rotating 
diamond core drill is ultrasonically vibrated in elliptical pattern and the process does not require pumping of the coolant. According to their experimental investigations, the cutting force and torque were reduced significantly, and the delamination at the exit of hole and surface quality around the hole edges were improved by comparing with traditional drilling (Liu et al., 2012).

\section{Concluding remarks}

Large amount of research work on UVAG has been carried out. The research work included both theoretical and experimental investigations. This paper reviewed the literature on experimental investigations of UVAG. Tables 1-7 summarise experimental investigations reported on seven outputs variables in details.

According to these tables, among all reported experimental investigations, only two types of ductile materials ( $\mathrm{Ti}$ and stainless steel) have been investigated and more effort has started on carbon fibre composites. But totally only eight input variables are studied in these experiments. Thus, in order to comprehensively understand the mechanisms of UVAG of ductile materials and carbon fibre composites, one future research direction could be to investigate more input variables and more types of ductile materials and composite materials.

In contrast, more brittle materials have been investigated. However, there are many blanks that need to be filled in this area. It should be noted that, in UVAG of brittle materials, there existed two types of machines: constant pressure and constant feedrate. Using constant federate machines has become the main trend, and most of research work were experimental investigations. The mechanisms in UVAG have not been comprehended, so the mechanisms in UVAG using constant federate machines could be the second research direction in the future.

From Section 3 to Section 7, mechanical properties of workpiece material may play an important role for the inconsistence among the reported experimental results. However, no reports have been focused on this topic. In order to understand and explain these inconsistencies, mechanical properties of workpiece material could be the third research direction.

Several DOE experiments have been designed to study interaction effects of input variables on outputs. It has been showed that even for same material, different researchers got different experiment results in some cases. This may be due to their different experimental conditions, but also may be due to the incomprehensive number of input variables and different data range of variables. Ultrasonic vibration amplitude, rotational speed and feedrate are the most frequently studied inputs variables. While for diamond grain size and concentration, bond type and diamond type, diameter of tool, higher cost and longer duration time will be required to study these inputs variables, so just a few experiments has been conducted to study these variables. Especially for vibration frequency, there is no choice to change the frequency on most UVAG machines since it has been fixed when the machines were built. All these can be the reasons why only a few input variables have been used in DOE experimental investigations. With the development of the UVAG device and the increasing new applications of UVAG, it is possible and necessary to make a more comprehensive study on UVAG.

Tool wear could be another research direction. To date only little research has been done on this topic. What has been done about tool wear focused on experimental 
observation, while the tool wear mechanism is still not understood yet. Many input variables can affect tool wear, such as tool design, machining parameters, coolant, workpiece, etc, but most of these input variables have not been systematically studied.

The new machining method RUEM was only used to machine CFRP, and both the experimental and theoretical studies are not sufficient to evaluate it. Therefore, this may be another research direction.

\section{Acknowledgements}

This study was supported by National Nature Science Foundation of China (Grant No. 51305369), China Postdoctoral Science Foundation (Grant No. 2012M521708), Research Fund for the Doctoral Program of Higher Education of China (Grant No. 20130184120007), the Fundamental Research Funds for the Central Universities (Grant No. SWJTU11CX023), and Key Laboratory Open Fund of the Ministry of Education (Grant No.JMTZ201605).

\section{References}

Ahmed, Y., Cong, W.L., Stanco, M.R., Xu, Z.G., Pei, Z.J., Treadwell, C., Zhu, Y.L. and Li, Z.C. (2012) 'Rotary ultrasonic machining of alumina dental cerarnics: a preliminary experimental study on surface and subsurface damages', Journal of Manufacturing Science and Engineering, Vol. 134, No. 6, pp.064501-064505.

Anantha Ramu, B.L., Krishnamurthy, R. and Gokularathnam, C.V. (1989) 'Machining performance of toughened zirconia ceramic and cold compact alumina ceramic in ultrasonic drilling', Journal of Mechanical Working Technology, Vol. 20, No. 89, pp.365-375.

Cho, S., Huh, Y., Yoon, K. and Ogawa, T. (1994) 'Aspects in grinding of ceramics', Journal of American Ceramic Society, Vol. 77, No. 9, pp.2443-2444.

Churi, N.J., Li, Z.C., Pei, Z.J. and Treadwell, C. (2005) 'Rotary ultrasonic machining of titanium alloy: a feasibility study', Proc 2005 ASME International Mechanical Engineering Congress and Exposition (IMECE), Orlando, FL.

Churi, N.J., Pei, Z.J. and Treadwell, C. (2006) 'Rotary ultrasonic machining of titanium alloy: effects of machining variables', Maching Science and Technology, Vol. 10, No. 3, pp.301-321.

Churi, N.J., Pei, Z.J. and Treadwell, C. (2007a) 'Experimental investigations on rotary ultrasonic machining of hard-to-machine materials', in Han, Q.Y. (Ed.): 'Materials processing under the influence of external fields', Proceedings of the 2007 TMS Annual Meeting \& Exhibition, 25 February - 1 March, Orlando, FL139-144.

Churi, N.J., Pei, Z.J. and TreadwelL, C. (2007b) 'Rotary ultrasonic machining of titanium alloy (ti-6al-4v): effects of tool variables', International Journal of Precision Technology, Vol. 1, No. 1, pp.85-96.

Churi, N.J., Pei, Z.J. and Treadwell, C. (2007c) 'Wheel wear mechanisms in rotary ultrasonic machining of titanium', Proceedings of 2007 ASME International Mechanical Engineering Congress and Exposition, Seattle, Washington, USA.

Churi, N.J., Pei, Z.J., Shorter, D.C. and Treadwell, C. (2007d) 'Rotary ultrasonic machining of silicon carbide: designed experiments', International Journal of Manufacturing Technology and Management, Vol. 12, Nos. 1-3, pp.284-298.

Churi, N.J., Pei, Z.J., Treadwell, C. and Shorter, D. (2009) 'Rotary ultrasonic machining of dental ceramics', International Journal of Machining and Machinability of Materials, Vol. 6, Nos. 3-4, pp.270-284. 
Cleave, D.V. (1976) 'Ultrasonic gets bigger jobs in mach ining and welding', Iron Age, Vol. 13, pp.69-72.

Cong, W.L, Wu, N., Tian, Y., Pei, Z.J. and Wang, X.W. (2012a) 'Edge chipping in rotary ultrasonic machining of silicon', International Journal of Manufacturing Research, Vol. 7, No. 3, pp.250-261.

Cong, W.L., Pei, Z.J., Deines, T.W., Srivastava, A., Riley, L. and Treadwell, C. (2012b) 'Rotary ultrasonic machining of CFRP composites: a study on power consumption', Ultrasonics, Vol. 52, No. 8, pp.1030-1037.

Cong, W.L., Pei, Z.J., Feng, Q., Deines, T.W. and Treadwell, C. (2012c) 'Rotary ultrasonic machining of CFRP: a comparison with twist drilling', Journal of Reinforced Plastics and Composites, Vol. 31, No. 5, pp.313-321.

Cong, W.L., Zou, X.T., Deines, T.W., Wu, N., Wang, X.W. and Pei, Z.J. (2012d) 'Rotary ultrasonic machining of carbon fiber reinforced plastic composites: an experimental study on cutting temperature', Journal of Reinforced Plastics and Composites, Vol. 31, No. 22, pp.1516-1525.

Cong, W.L., Feng, Q., Pei, Z.J., Deines, D.W. and Treadwell, C. (2011) 'Rotary ultrasonic machining of carbon fiber-reinforced plastic composites: using cutting fluid vs. cold air as coolant', Journal of Composite Materials, Vol. 46, No. 14, pp.1745-1753.

Cong, W.L., Pei, Z.J. and Wang, Q.G. (2009a) 'Surface roughness in rotary ultrasonic machining of stainless steels', Proceedings of the 2009 Industrial Engineering Research Conference.

Cong, W.L., Pei, Z.J., Churi, N.J. and Wang, Q.G. (2009b) 'Rotary ultrasonic machining of stainless steel: design of experiments', Transactions of the North American Manufacturing Research Institution of SME, Vol. 37, No. 1, pp.261-268.

Cong, W.L., Pei, Z.J., Deines, T., Wang, Q.G. and Treadwell, C. (2010) 'Rotary ultrasonic machining of stainless steels: empirical study of machining variables', International Journal of Manufacturing Research, Vol. 5, No. 3, pp.370-385.

Cong, W.L., Pei, Z.J., Deines, T.W., Liu, D.F. and Treadwell, C. (2013a) 'Rotary ultrasonic machining of CFRP/Ti stacks using variable feedrate', Composites: Part B, Vol. 52, No. 52, pp.303-310.

Cong, W.L., Pei, Z.J., Deines, T.W., Zhang, P.F. and Treadwell, C. (2013b) 'Surface roughness in rotary ultrasonic machining:Hypotheses and their testing via experiments and simulations', International Journal of Manufacturing Research, Vol. 8, No. 4, pp.378-393.

Cusumano, J., Huber, J. and Marshall, K.T. (1974) 'Ultrasonic drilling of boron fiber composite', Modern Plastics, Vol. 52, No. 6, pp.88-90.

Dam, H., Jensen, J. and Quist, P. (1993) 'Surface characterization of ultrasonic machined ceramics with diamond impregnated sonotrode', Machining of Advanced Materials, NIST Special Publication, Vol. 847, pp.125-133.

Feng, Q., Cong, W.L., Pei, Z.J. and Ren, C.Z. (2012) 'Rotary ultrasonic machining of carbon fiber-reinforced polymer: feasibility study', Machining Science and Technology, Vol. 16, No. 3, pp.380-398.

Graff, K.F. (1975) 'Ultrasonic machining', Ultrasonics, Vol. 13, No. 3, pp.103-109.

Hagiwara, S., Obikawa, T., Iwata, S. and Usui, E. (1994) 'Edge fracture characteristics of diamond grains in stone grinding process', Nippon Kikai Gakkai Ronbunshu, Vol. 60, No. 577, pp.2917-2923.

Hards, K.W. (1966) 'Ultrasonic speed diamond machining', Ceramics Age, Vol. 82, No. 12, pp.34-36.

Hocheng, H., Tai, N.H. and Liu, C.S. (2000) 'Assessment of ultasronic drilling of C/SiC composite material', Composites: Part A, Vol. 31, No. 2, pp.132-142.

Jiao, Y., Hu, P., Pei, Z.J. and Treadwell, C. (2005a) 'Rotary ultrasonic machining of ceramics: design of experiments', International Journal of Manufacturing Technology and Management, Vol. 7, Nos. 2-4, pp.192-206. 
Jiao, Y., Liu, W.J., Pei, Z.J., Xin, X.J. and Treadwell, C. (2005b) 'Study on edge chipping in rotary ultrasonic machining on ceramics: an integration of designed experiment and fem analysis', Journal of Manufacturing Science and Engineering, Vol. 127, No. 4, pp.752-758.

Kim, D., Ramulu, M. and Garbini, J. (2001) 'Hole quality in drilling of graphite/bismalemidetitanium stacks', Advancing Affordable Materials Technology, Vol. 5, No. 8, pp.315-326.

Komaraiah, M. and Reddy, P.N. (1991) 'Rotary ultrasonic machining - a new cutting process and its performance', International Journal of Production Research, Vol. 29, No. 11, pp.2177-2187.

Kremer, D.; Lhiaubet, C. and Moisan, A. (1991) 'A study of the effect of synchronizing ultrasonic vibrations with pulse in EDM', Annals of CIRP, Vol. 40, No. 1, pp.211-214.

Kubota, M., Tamura, Y. and Shimamura, N. (1977) 'Ultrasonic machining with a diamond impregnated tool', Bulletin of Japanese Society of Precess Engine, Vol. 11, No. 3, pp.127-132.

Kumar, J. (2013) 'Ultrasonic machining - a comprehensive review', Machining Science and Technology, Vol. 17, No. 3, pp.325-379.

Legge, P. (1964) 'Ultrasonic drilling of ceramics', Industrial Diamond Review, Vol. 24, pp.20-24.

Li, Z.C., Cai, L.W., Pei, Z.J. and Treadwell, C. (2004a) 'Finite element simulation of rotary ultrasonic machining of advanced ceramics', Proceeding of ASME International Mechanical Engineering Congress and Exposition, Anaheim, CA, USA.

Li, Z.C., Jiao, Y., Deines, T.W., Pei, Z.J. and Treadwell, C. (2004b) 'Experimental study on rotary ultrasonic machining of poly-crystalline diamond compact', Proceedings of 2004 IIE Annual Conference and Exhibition, pp.769-774.

Li, Z.C., Cai, L.W., Pei, Z.J. and Treadwell, C. (2006) 'Edge-chipping reduction in rotary ultrasonic machining of ceramics: finite element analysis and experimental verification', International Journal of Maehine Tools \& Manufacture, Vol. 46, No. S12-13, pp.1469-1477.

Li, Z.C., Jiao, Y., Deines, T.W., Pei, Z.J. and Treadwell, C. (2005a) 'Rotary ultrasonic machining of ceramic matrix composites: feasibility study and designed experiments', International Journal of Machine Tools and Manufacture, Vol. 45, Nos. 12-13, pp.1402-1411.

Li, Z.C., Jiao, Y., Deines, T.W.; Pei, Z.J. and Treadwell, C. (2005b) 'Development of innovative coolant system for rotary ultrasonic machining', International Journal of Manufacturing Technology and Management, Vol. 7, No. 4, pp.318-328.

Li, Z.C., Pei, Z.J., Kwon, P., Zeng, W.M. and Treadwell, C. (2005c) 'Experimental study on cutting force in rotary ultrasonic machining of zicronia/alumina composites', Transactions of the North American Manufacturing Research Institute of SME, Vol. 33, pp.89-96.

Liu, J., Zhang, D.Y., Qin, L.G. and Yan, L.S. (2012) 'Feasibility study of the rotary ultrasonic elliptical machining of carbon fiber reinforced plastics (CFRP)', International Journal of Machine Tools \& Manufacture, Vol. 53, No. 1, pp.141-150.

Lv, D.X., Tang, Y.J., Wang, H.X. and Huang, Y.H. (2014) 'Experimental investigations on subsurface damage in rotary ultrasonic machining of glass bk7', Machining Science and Technology, Vol. 17, No. 3, pp.443-463.

Lv, D.X., Wang, H.X., Tang, Y.J., Huang, Y.H., Zhang, H.J. and Ren, W. (2012) 'Surface observations and material removal mechanisms in rotary ultrasonic machining of brittle material', Proceedings of the Institution of Mechanical Engineers, Part B: Journal of Engineering Manufacture, Vol. 226, No. 9, pp.1479-1488.

Ma, F.J. (2013) 'The Development of Ultrasonic Assisted Machining System and its Application in Machining of Composite, Dalian University of Technology, Dalian.

Malkin, S. (1989) Theory and Applications of Machining with Abrasives, Ellis Horwood Limited Chichester, West Sussex, UK.

Markov, A.I. (1977) 'Ultrasonic drilling and milling of hard non-metallic materials with diamond tools', Machine \& Tooling, Vol. 48, No. 9, pp.45-47. 
Ng, S., Le, D., Tucker, S. and Zhang, G. (1996) 'Control of machining induced edge chipping on glass ceramics', Proceedings of the 1996 ASME International Mechanical Engineering Congress and Exposition, Manufacturing Engineering Division, Atlanta, GA, USA.

Pei, Z.J., Khann, N. and Ferrira, P.M. (1995) 'Rotary ultrasonic machining of structure ceramics-a review', Ceramic Engineering and Science Proceedings, Vol. 16, No. 259, pp.259-278.

Petrukha, P.G. (1970) 'Ultrasonic diamond drilling of deep holes in brittle materials', Russian Engineering Journal, Vol. 50, No. 10, pp.70-74.

Prabhakar, D. (1992) Machining Advanced Ceramic Materials Using Rotary Ultrasonic Machining Process, University of Illinois at Urbana-Champaign, Illinois.

Prabhakar, D., Ferreira, P.M. and Haselkorn, M. (1992) 'An experimental investigation of material removal rates in rotary ultrasonic machining', Transactions of the North American Manufacturing Research Institute of SME, Vol. 20, pp.211-218.

Prabhakar, D., Pei, Z.J., Ferreira, P.M. and Haselkorn, M. (1993) 'A theoretical model for predicting material removal rates in rotary ultrasonic machining of ceramics', Transactions of the North American Manufacturing Research Institution of SME, Vol. 21, pp.167-172.

Prtrukha, P.G. (1970) 'Ultrasonic diamond drilling of deep holes in brittle materials', Russian Engineering Journal, Vol. 50, No. 10, pp.70-74.

Qin, N., Pei, Z.J., Cong, W.L. and Guo, D.M. (2010) 'Effects of tool design on edge chipping in ultrasonic-vibration-assisted grinding', Proceedings of the 2010 International Manufacturing Science \& Engineering Conference (MSEC), Erie, Pennsylvania, USA, 12-15 October.

Salmon, S.C. (1992) Modern Grinding Process Technology, McGraw-Hill, New York.

Sathyanarayanan, G. and Pandit, S. (1985) 'Fracture and attritious wear in grinding by data dependent systems', 13th North American Manufacturing Research Conference Proceedings, Manufacturing Engineering Transactions, Berkeley, CA314-320.

Shi, Z. and Malkin, S. (2003) 'An investigation of grinding with electroplated CBN wheels', CIRP Annals - Manufacturing Technology, Vol. 52, No. 1, pp.267-270.

Stoica, G.F., Capitanescu, C. and Biolan, A.I. (2003) 'Wear behavior of thin coatings based on diamond', Proceedings of National Tribology Conference, Galati, Romania, 24-26 September, pp.133-135.

Thomas, T.R. (1999) Rough Surfaces, Imperial College Press, London.

Tyrrell, W.R. (1970) Rotary Ultrasonic Machining, SME Technical Paper MR.70-5161970.

Wang, H.M.S. and Lin, L.Y. (1993) 'Improvement of rotary ultrasonic deep hole drilling of glass ceramics - Zerodur', Seminar of The 7th International Precision Engineering, May; Kobe, Japan.

Wang, Q.G., Cong, W.L., Pei, Z.J., Gao, H. and Kang, R.K. (2009) 'Rotary ultrasonic machining of potassium dihydrogen phosphate (KDP) crystal: an experimental investigation on surface roughness', Journal of Manufacturing Processes, Vol. 11, No. 2, pp.66-73.

Web [online] http 1://www.diamondbladeselect.com/tips/diamond-tools-how-to-choose-diamondconcentration/ (accessed 2012).

Xie, Z., Moon, R., Hoffman, M., Munroe, P. and Cheng, Y. (2003) 'Role of microstructure in the grinding and polishing of a-sialon ceramics', Journal of European Ceramic Society, Vol. 23, No. 13 , pp.2351-2360.

Ya, G., Qin, H.W., Xu, Y.W. and Zhang, Y.S. (2001) 'An experimental investigation on rotary ultrasonic machining', Key Engineering Materials, Vols. 202-203, pp.277-280.

Zeng, W.M., Li, Z.C., Pei, Z.J. and Treadwell, C. (2004) 'Tool wear in rotary ultrasonic machining of advanced ceramics', 7th International Conference on Progress of Machining Technology, 8-11 December, Suzhou, China.

Zeng, W.M., Li, Z.C., Pei, Z.J. and Treadwell, C. (2005) 'Experimental observation of tool wear in rotary ultrasonic machining of advanced ceramics', International Journal of Machine Tools and Manufacture, Vol. 45, Nos. 12-13, pp.1468-1473. 
Zeng, W.M., Li, Z.C., Xu, X.P., Pei, Z.J., Liu, J.D. and Pi, J. (2008) 'Experimental investigation of intermittent rotary ultrasonic machining', Key Engineering Materials, Vol. 359-360, pp.425-430.

Zeng, W.M., Xu, X.P. and Pei, Z.J. (2006) 'Rotary ultrasonic machining of advanced ceramics', Materials Science Forum, Vols. 532-533, pp.361-364.

Zeng, W.M., Xu, X.P. and Pei, Z.J. (2009) 'Experimental investigation of tool wear in rotary ultrasonic machining of alumina', Key Engineering Materials, Vol. 416, pp.182-186.

Zhao, C.Y., Gong, H., Fang, F.Z. and Zhan, Z.L. (2013) 'Experimental study on the cutting force difference between rotary ultrasonic machining and conventional diamond grinding of $\mathrm{k} 9$ glass', Machining Science and Technology, Vol. 17, No. 1, pp.129-144.

Zou, X.T., Cong, W.L., Wu, N. and Tian, Y. (2013) 'Cutting temperature in rotary ultrasonic machining of titanium Experimental study using novel Fabry-Perot fibre optic sensors', International Journal of Manufacturing Research, Vol. 8, No. 3, pp.250-261. 